NBER WORKING PAPER SERIES

\title{
CAN FOREIGN AID ACCELERATE STABILIZATION?
}

\author{
Alessandra Casella \\ Barry Eichengreen
}

Working Paper No. 4694

\section{NATIONAL BUREAU OF ECONOMIC RESEARCH 1050 Massachusetts Avenue \\ Cambridge, MA 02138 \\ April 1994}

This paper is a part of the NBER's research program in International Finance and Macroeconomics. Any opinions expressed are those of the authors and not those of the National Bureau of Economic Research. 


\title{
NBER Working Paper $\$ 4694$
}

April 1994

\section{CAN FOREIGN AID ACCELERATE \\ STABILIZATION?}

\begin{abstract}
This paper studies the effect of foreign aid on economic stabilization. Following Alesina and Drazen (1991), we model the delay in stabilizing as the result of a distributional struggle: reforms are postponed because they are costly and each distributional faction hopes to reduce its share of the cost by outlasting its opponents in obstructing the required policies. Since the delay is used to signal each faction's strength, the effect of the transfer depends on the role it plays in the release of information. We show that this role depends on the timing of the transfer: foreign aid decided and transferred sufficiently early into the game leads to earlier stabilization; but aid decided or transferred too late is destabilizing and encourages further postponement of reforms.
\end{abstract}

\author{
Alessandra Casella \\ Department of Economics \\ Columbia University \\ New York, NY 10027 \\ and NBER
}

\author{
Barry Eichengreen \\ Department of Economics \\ University of Califomia, Berkeley \\ Berkeley, CA 94720 \\ and NBER
}




\section{INTRODUCTION}

The transition from central planning to the market in Eastern Europe and the former Soviet Union has been characterized by a host of economic difficulties. Prominent among these are large budget deficits leading to rapid rates of monetization and high inflation. Inflation has distorted relative prices, disrupted embryonic markets and undermined support for reform. While the need for stabilization is clear, observers disagree about the political and economic prerequisites for bringing it about. One debate concerns the role of foreign assistance. On one side are those who argue that Western aid can play a critical role in halting inflation'. External resources, they argue, can defuse distributional contlicts over the tax increases and spending cuts needed for fiscal balance and stabilization. By moderating the swdfices required of those who agree to bear the cost of stabilization, aid can hasten adjustment. On the other side are those who argue that aid will only delay the adoption of the requisite policies. ${ }^{2}$ Financial assistance, they wam, reduces the pain of living with inflation. By endowing vested interests with additional resources, aid will encourage them to resist adjustment and put off the day of reckoning.

The literature does not offer a systematic analysis of the validity of these points of view. Providing a first step towards such an analysis is our goal in this paper.

Arialyzing the impact of aid on the timing of stabilization requires us to posit an explanation for the persistence of the inflation that is the policy problem. Given the prominence of distributional considerations in the arguments of advocates and opponents of Western stabilization alike, we employ a theoretical set-up in which distributional conflict is key. In a recent article, Alesina and Drazen (1991) have provided such a model. They analyze inflation persistence as the byproduct of a distributional war of attrition between interest groups 
uncertain about the capacity of their rivals to bear the costs of inflation. Athough all interest groups understand that restrictive policies will eventually have to be adopted, and although all groups suffer while stabilization is being delayed, each one has an incentive to resist the adoption of the relevant measures since it hopes that another group will capitulate first and bear the entire burden of adjustment. Inflation therefore persists until the weakest faction concedes.

We argue that this set-up captures the essence of the mechanism underlying many of the inflations whose persistence has prompted discussion of foreign aid. For example, the German hyperinflation of 1923, in response to which the Dawes Loan was offered to buttress stabilization, is commonly interpreted in terms of a distributional conflict between German industrialists who demanded reductions in real wages and increases in hours of work to finance reparations payments, and workers who pressed for a capital levy or other forms of wealth taxation to raise the requisite funds.' Other post World War I Central and Eastem Europe inflations, in response to which stabilization loans were extended, are similarly interpreted in distributional terms." The Polish inflation, whose end in 1926 coincided with a credit granted by a consortium of foreign central banks, for example, is commonly described as the outgrowth of a struggle between workers and capitalists." Our analysis of inflation and stabilization in post World War II France and Italy similarly concludes that reform was posponed because of a distributional conflict between capital and labor and assigns to U.S. aid a pivotal role in bringing about the ultimate stablization." Eichengreen and Uzan (1992) argue that the Marshall Plan defused distributional conflict and tacilitated stabilization not only in Italy and France but in many of the European countries receiving American aid. To cite yet another example, distributional conflicts figure prominently in cases, in Latin America and eisewhere, where IMF stand-by loans have been proposed as a means of encouraging stabilization.' And the distributional interpretation of inflation in Russia and other post-Soviet 
republics has been encouraged by evidence of increasing income inequality, tax avoidance. and disputes between enterprise managers and finance ministry officials over inter-enterprise arrears, all of which has fed the debate over the efficacy of foreign aid.

Since Alesina and Drazen's model is familiar, we adopt their formulation. Our innovation is to add foreign aid. The critical assumption is that aid is not extended instantaneously upon the advent of inflationary pressures. This assumption is both critical to our results and - we believe - eminently plausible. Whether to provide financial assistance to a foreign country struggling with inflation is always a contentious issue. First the existence of an inflation problem must be identified. Then the case for aid has to be made. A coalition supporting it has to be formed in the donor country. Finally a mechanism has to be created for delivering the assistance. Each of these steps is a source of delay between the onset of inflation, the announcernent of aid and its arrival. Such delays feature prominently in virtually all instances where foreign assistance has been provided. In the case of the Dawes Loan, Germany had suffered several months of inflation before a Committee of Experts was appointed; the Dawes Loan was then raised in 1924, months after stabilization commenced. The countries of Central and Eastem Europe experienced prolonged inflations before the League of Nations and foreign governments made credible offers of financial assistance. General George Marshall's speech at Harvard University in June 1947, making the case for the Marshall Plan, culminated a long debate within the U.S. government over the advisability of aid and preceded by six months Congressional debate of the proposal. Similarly, the merits of Westem aid to Russia were discussed for more than a year before the G-7 countries assernbled a package of $\$ 24$ billion in mid-1992. Since then debate has continued, and at the time of writing the bulk of the funds has yet to be disbursed.

In our analysis, the effects of aid tum out to hinge on precisely these issues of timing. Athough some delay is inevitable, our conclusion is that too long a delay makes aid counterproductive. Aid announced and disbursed relatively rapidly can hasten stabilization. 
Aid which is offered too late has the opposite effect.

This result obtains because a foreign transfer has two conflicting effects. On the one hand, the knowledge that aid will eventually be forthcoming can encourage early stabilization by lightening the fiscal burden on the faction whose acceptance of a larger share of taxes brings about the stabilization. The cost of stabilization will be less if some fraction of the budget deficit is closed by foreign aid; this encourages the group least able to endure continuous inflation to agree to underwrite the remaining gap. On the other hand, the delay which ensues between the announcement of aid and its disbursal provides an incentive for each faction to postpone offering concessions until the assistance actually arrives. Since the sacrifice required to effect stabilization is larger before the aid arrives than after, each group has an incentive to wait until the assistance materializes. For each group, the relative importance of these two effects depends on the costs of inflation. If the costs of inflation are high, then the first effect dominates: the reduction in the cost of conceding is sufficient to bring forward the optimal date of concession. If instead such costs are low, then it is optimal to wait for the transfer.

If the transfer is announced in the early phases of the inflation, even interest groups which suffer greatly from price instability would not have conceded yet. They would now find it optimal to concede at once. If no concession occurs, all groups can deduce that their opponents do not experience very high costs of inflation: the release of information is accelerated. On the other hand, if aid is announced late in the game, everyone knows that all groups will then prefer to wait until the transfer is disbursed: the announcement delays the flow of information and the date of stabilization. In conclusion, when stabilization is delayed by each group's belief that it may be able to outlast its opponents, the result of any intervention depends on its effect on the transmission of Information. Aid may serve as a revelation mechanism whose effectiveness depends on approprlate timing.

As this discussion makes clear, we do not modei the conditions that donor countries attach 
to foreign aid. The effectiveness of conditionality is a disputed issue, however, and the most accurate way of specifying it is unclear. And from a logical point of view it seems natural to begin by studying the simpler case of unconditional aid.

Section II of the paper lays out the basic model, while Section III introduces foreign aid. Section IV discusses the sensitivity of the results to specitic assumptions of the model, and section $V$ concludes.

\section{STABILIZATION IN A WAR OF ATTAITION MODEL}

Alesina and Drazen describe an economy where government deficits are financed by distortionary taxes (a proxy for inflation) which impose welfare losses to consumers. These welfare losses differ across consumers' types, are private Information and could be avoided if consumers agreed to 'stabilize" the economy, that is if an agreement emerged on higher (but not distortionary) taxes or lower government transters. The authors assume that the costs of stabilization are borne unevenly, with the group conceding first incurring the largest share. In equilibrium, each faction hesitates to concede, hoping to outlast lits rivals. Although a fullyinformed social planner would stabilize immediately, delay is individually rational.

The model can be summarized briefly.

(1) The game starts with a given stock of outstanding bonds ( $\left.b_{0}\right)$, and a given level of primary government expenditures $\left(g_{0}\right)$. For simplicity, $g_{0}$ is constant forever. Prior to stabilization, in each period a proportion $\mu$ of total government spending is financed by distortionary taxes, the rest by new bond issues. At time $t$, total public expenditure $f$ is:

$$
h=r b \theta^{11+1 n}
$$

where $r$ is the constant interest rate, $b \equiv b_{0}+g_{d} / r$, and the exponential term captures the 
accumulation of debt over time. Taxes at time $t_{1} \tau_{1}$, are therefore

$$
\tau_{1}=\mu \mathrm{rbe} e^{(1 \cdot) / n}
$$

(2) There are two consumers, both earning the same constant income $y$ and paying an equal share of taxes in each period. Besides reducing consumers' disposable incomes, taxes cause distortions which result in utility losses. These losses are assumed proportional to the amount of taxes but different across consumers; they are captured by a parameter $\theta_{1}$, which is private information.

In equilibrium, each player consumes his disposable income. Ignoring the income term (which is constant), the two players' flow utilities each period (before stabilization) are:

$$
u_{1}=-\left(\theta_{1}+1 / 2\right) \mu r b e^{\prime \prime n n} \quad i=1,2
$$

$\theta$, lies between known extremes $\underline{\theta}$ and $\bar{\theta}$. Both players estimate the opponent's $\cos t \theta$ according to the density function $f(\theta)$ and cumulative probability distribution function $F(\theta)$.

(3) At the date of stabilization T. non-distortionary taxes become available and are raised so as to cover all fiscal expenditure. These taxes are divided unequally between players, with the player conceding first - the "loser - shouldering a larger tax burden forever. The tax shares of the "loser" and the "winner" are $a$ (larger than 1/2) and (1-a), respectively. With public expenditure completely tinanced by taxes, debt subsequently remains constant, as do total fiscal expenditures and taxes.

Since taxes are non-distortionary, the only utility loss following stabilization is that associated with the reduction in disposable income. Flow utility at time $T$ is:

$$
\begin{aligned}
& U^{b}=-a r b \theta^{11 w d r} \\
& U^{m}=-(1-a) \text { be } \theta^{11+1+d}
\end{aligned}
$$


where $L$ denotes the "loser, $W$ the "winner. The shares $\alpha$ and $(1-\alpha)$ simply multiply total fiscal expenditures at $T$. Since no new debt accumulates over time, flow utility remains constant for both players forever. Discounted lifetime utility evaluated at $T$ is:

$$
\begin{aligned}
& V^{\prime}=-\alpha b e^{(1 m+T)} \\
& V^{m}=-(1-a) b e^{(1, w) !}
\end{aligned}
$$

(4) Each player's problem is simply described. In each period, he can concede and bring about stabilization by agreeing to pay higher taxes forever. Atternatively, he can wait, hoping that his opponent will concede but enduring distortionary taxes in the interim. The solution of the game is a function $T\left(\theta_{i}\right)$ mapping the idiosyncratic cost of living in the destabilized economy $\theta_{1}$ into an optimal time of concession $T$. In equilibrium, $T$ is such that the marginal benefit of conceding at $T$ instead of at $T+d t$ equals the marginal benefit of waiting:

$$
\left.\left(-u_{1}+U^{L} \cdot d V^{\prime} / d T\right)=H\left(T, \theta_{1}\right) N^{\prime \prime}-V^{\prime}\right)
$$

where $H\left(T, \theta_{j}\right)$ is the probability that the opponent concedes between $T$ and $T+d t$, given that he has not yet conceded, and is given by:

$$
H\left(T, \theta_{i}\right)=-\frac{f\left(\theta_{i}\right)}{F\left(\theta_{i}\right)} \frac{1}{T^{\prime}\left(\theta_{i}\right)}
$$

where the prime sign indicates the first derivative.

Substituting the functional forms assumed above and concentrating on the symmetric equilibrium, equation (6) can be written as:

$$
T^{\prime}(\theta)=-\frac{f(\theta)}{F(\theta)} \frac{(2 \alpha-1)}{r \mu(\theta+1 / 2-\alpha)}
$$


The additional assumption $\underline{\theta}>\alpha \cdot 1 / 2$ guarantees that all types $\theta>\underline{\theta}$ concede in finite time. As shown by (8), and as usual in wars of attrition, the optimal concession time $T$ depends negatively on $\theta$ : the higher is the idiosyncratic cost from distortionary taxation, the earlier a player concedes.

Moreover, the player with the highest possible cost, $\bar{\theta}$, concedes immediately, since he knows that any other type will wait at least a bit. Therefore:

$$
T(\bar{\theta})=0
$$

The differential equation (8) together with the boundary condition (9) completely characterize the symmetrical equilibrium. If, for example, the distribution of $\theta$ is uniform between $\underline{\theta}$ and $\bar{\theta}$. (8) and (9) imply:

$$
T(\theta)=\frac{(2 a-1)}{\Gamma \mu(\underline{\theta}+1 / 2-a)}\left[\ln \frac{\theta+1 / 2-a}{\bar{\theta}+1 / 2-a} \cdot \ln \frac{\theta \underline{\theta}}{\bar{\theta}-\underline{\theta}}\right]
$$

This function is shown in Figure 1.

\section{STABIUZATION AND FOREIGN AID}

We now study the effect of a foreign transfer on the expected time of stabilization. We model the transfer as accruing to the government, not directly to consumers, an assumption consistent with the historical episodes described in Section $\mathrm{l}$. Assume that at time v foreign aid arrives in the country. It is used to withdraw a proportion (1-B) of outstanding government debt and to reduce intermal financing of direct public expenditure by the same proportion (1-B), with $B$ between 0 and 1. For simplicity, the reduction in direct public expenditure is assumed to 
continue forever." From time v onward, total fiscal expenditure is then given by:

$$
f_{t}=B r b e^{(1+\ln )} \quad t \geq v
$$

It is simple to verify that conditions (8) and (9) remain unchanged: the optimal time of concession does not depend on the size of the budget and therefore is invariant with respect to changes in fiscal policy. The assumption that the welfare costs of distortlonary taxes are directly proportional to the tax bill implies that the level of fiscal expenditures cancels out in equation (8): a cut in public spending has an identical effect on the marginal benefit of conceding and on the marginal benefit of waiting. Since in addition fiscal retrenchment does not affect the boundary condition, unanticipated foreign aid has no influence on the timing of stabilization. We discuss this point further in Section IV.

In point of fact, foreign aid hardly occurs as an unexpected event. It is demanded repeatedly by the prospective recipients and is the subject of bargaining and debate. We therefore turn next to the case of anticipated aid.

Suppose that at time $s$ it is announced that aid will arrive (with certainty) at time v.' As before, aid will be used to withdraw public debt and reduce internal financing of public expenditure. If stabilization has not taken place by time $v$, after the transfer has arrived the game continues along the path described by equation (8).

Consider the players' problem in the interval between $s$ and $v$. Immediately following the announcement and before the transfer has arrived, the welfare loss from distortionary taxes and the one-period cost of conceding are unchanged, since the level of government spending to be financed remains the same. However, lifetime utilities after the stabilization are affected by the knowledge that public spending will be reduced from v onward. If the date of stabilization $T$ falis in the interval between $s$ and $v:$

$$
V=-a b e^{(1+w)+T}\left[1-(1-\beta) e^{-1+n)}\right]
$$




$$
V^{w}=-(1-a) b e^{(1+w i r)}\left[1-(1-\beta) e^{+m+n}\right] \quad T \in[s, V]
$$

Define:

$$
\sigma(t) \equiv 1-(1-\beta) e^{\cdot 1+\infty} \quad t \in[s, v]
$$

$\sigma(t)$ is always positive but smaller than 1 , is decreasing in $t$ and equals $B$ when $t$ equals $v$.

The anticipation of the transfer has two effects. First, since the loser will finance the larger share of public spending after stabilization, the anticipation of foreign aid (which reduces the fiscal burden) diminishes the marginal cost of conceding. Ceteris paribus, this should hasten stabilization. At the same time, however, since deficit reduction takes place only after the aid is transfered, there is an incentive to postpone conceding until closer to that moment. The overall influence on the time of concession is determined by the relative weight of these two considerations. $^{10}$

Let $T(\theta)$ denote the function describing the optimal time of concession in the interval between s and v. Using (3). (4), (12) and (13), the marginal condition (6) becomes:

$$
T^{\prime}(\theta)=-\frac{f(\theta)}{F(\theta)} \frac{(2 \alpha-1) \sigma(\eta)}{r \mu(\theta+1 / 2-a)-\operatorname{ar}(2 \mu)(1-\sigma(\eta))}
$$

Assume for the moment that the denominator is strictly positive. Comparing (14) to (8), the slope of the function $T(\theta)$ is smaller than the slope of $T(\theta)$, in absolute value, if and only if:

$$
\frac{(\theta+1 / 2) \mu-2 \alpha}{\sigma(\eta)}>(\theta+1 / 2) \mu \cdot 2 \alpha
$$

Since $\sigma(\eta)$ is always smaller than 1 , condition $(15)$ is satisfied when:

$$
(\theta+1 / 2) \mu>2 \alpha
$$


independently of the value of $B$. We have no a priori reason to believe that (16) should be true for all $\theta$.

To conclude the characterization of the equilibrium, we must consider the possibility of a jump in the optimal path of concessions following the announcement of the transfer. Such a jump could have two causes. First, we have assumed so far that the denominator of equation $(14)$ is strictly positive, which occurs it:

$$
(\theta+1 / 2) \mu>2 \alpha-\alpha \sigma(\mathrm{T})(2-\mu)
$$

Condition (17) need not be satisfied. If it is violated, the marginal benefit from conceding is not positive: even if a player knows with certainty that his opponent will not concede, he still gains from delay. Since $\sigma(T)$ falls as $T$ rises, if at a given moment in time (17) is violated for all $\theta$ in the game it will continue to be so in the future. In usual wars of attrition, this would mean that the game has come to an end, with no possibility of further concessions. Here the situation is complicated by the knowledge that the game will change at time $v$, retuming to the path defined by equation ( $(8)$. Since $\underline{\theta}$ is larger than $(a-1 / 2)$, all players will eventually find it optimal to concede after time $v$. Imagine a player knowing with certainty that he will concede exactly at $v$, before his opponent: if (17) is violated he will nonetheless have no incentive to concede any earlier. The change in the game when the transfer is conveyed makes possible an expected discontinuity that is usually ruled out in wars of attrition.

A second possible source of discontinuity is a change in the boundary condition at the time the transfer is announced, triggering a probability mass of concessions. Since the announcement is unexpected, there is no reason to exclude this possibility a priori. A change in the boundary condition could occur if new information about the opponent's type is revealed, or if a player's cost from staying in the game has changed sufficiently that he prefers 
to concede even with a positive probability of winning in the next instant. In our formulation, however, no new information about the opponent is revealed at the time of the announcement, and no player ever wants to abandon the game. It follows that this second source of discontinuity can be ruled out.

Organizing these results, we can evaluate the effect of an expected transfer on the timing of stabilization. From time 0 to $s$, the solution to the game is described by (B) and (9). At time $s$, the marginal player who is just indifferent between conceding and waiting is of type $\theta_{0}$, where $\theta$, is defined by:

$$
T\left(\theta_{2}\right)=s
$$

Similarly, $\theta_{v}$, the player just indifferent between conceding and waiting at the moment the transfer is disbursed, is defined by:

$$
T\left(\theta_{1}\right)=v
$$

We can distinguish three cases.

\section{Case 1.}

Suppose $\theta$, is such that:

$$
\left(\theta_{v}+1 / 2\right) \mu \geq 2 \alpha
$$

Then, the marginal benefit from conceding is strictly positive for all $\theta$ larger or equal to $\theta_{v 1}$ and $T(\theta)$ is well-defined and decreasing in $\theta$. Since $v$ is larger than $s, \theta$, must be smaller than $\theta_{\text {. }}$ Therefore:

$$
\left(\theta_{1}+1 / 2\right) \mu>2 \alpha
$$

Two results follow. First, (20) implies that (17) is satisfied for all $\theta$ larger or equal to $\theta_{v}$ and the 
path of concessions has no discontinuities. During the interval between $s$ and $v$, this path is described by (14) and by the boundary condition:

$$
T\left(\theta_{.}\right)=s
$$

After $v$, the relevant equations are ( 8 ) and

$$
T\left(\theta_{.}\right)=v
$$

Second, the delay before stabilization is unambiguously shortened by the provision of ald. Since the game continues with the original slope after time $v$, whether stabilization is hastened or delayed depends on the steepness of the function $T(\theta)$ between $s$ and $v$, relative to the steepness of the original function $T(\theta)$. Condition $(20)$ guarantees that $T(\theta)$ is flatter than the original function at all points in the relevant interval: following the announcement of aid, the optimal time of concession is lower for all $\theta$, and stabilization is unambiguously accelerated. This case is depicted in Figure 2a."

\section{Case 2.}

Suppose instead that $\theta$, is such that:

$$
(\theta,+1 / 2) \mu \leq 2 a
$$

(which implies that (20) is violated). There are two possibilities. First, it may be that:

$$
(\theta .+1 / 2) \mu>2 a-\sigma \sigma(s)(2-\mu)
$$

In this case, the marginal benefit from conceding is strictly positive at $\theta_{n}$ and $T(\theta)$ is welldefined at the time the transfer is announced. Suppose there exists a $\theta^{*}$, smaller than $\theta_{0}$ for which the marginal benefit from conceding is 0 (i.e. for which (17) is violated). Then on the path defined by $T(\theta)$ the optimal delay before concession for $\theta^{*}$ is infinite. Since $T(\theta)$ is 
continuous in $\theta$, the slope of the optimal path tends to infinity asymptotically as $\theta$ approaches $\theta^{\circ}$. But then by construction $\theta$, must be larger than $\theta^{\circ}$, and $T(\theta)$ must be well-defined for all $\theta$ between $\theta$, and $\theta_{*}$. In other words, if there is any jump it must occur at time s when the transfer is first announced. Therefore (25) is sufficient to rule out discontinuities in the path of concessions: if (25) is satisfied, the path of concessions is defined by (14), is continuous, and the boundary conditions at times s and $v$ are (22) and (23), as before. However, (24) implies that $T(\theta)$ is steeper than the original function between $s$ and $v$, and the conclusion must be that the transfer delays stabilization. (See Figure 2b).

On the other hand, if equation (25) is violated, announcement of the transfer causes a discontinuity. Since all players still in the game must have costs lower than $\theta_{n}$, the marginal benefit of conceding is negative for all of them and continues to be negative as time passes and $\sigma$ fals. It follows that no one concedes between $s$ and $v$. At time $v$, when the transfer takes place, the path of concessions starts again, as described by (8) and the new boundary condition:

$$
T\left(\theta_{0}\right)=v
$$

Again, stabilization is delayed by the transfer (see Figure 2c).

\section{Case 3.}

An intermediate case exists when (21) is satisfied but (20) is violated:

$$
\left(\theta_{v}+1 / 2\right) \mu<2 \sigma
$$

In this case, discontinuities are ruled out (since (21) implies (25)), and the new path Is flatter than the original one at $s$ but steeper at $v$. The transfer may accelerate or postpone stabilization. (See Figure 2d).

These conclusions can be summarized in the following proposition: 
Proposition $A$. The announcement at time $s$ of a foreign transfer to arive at time $v$ may accelerate stabilization only if $\left(\theta_{0}+1 / 2\right) \mu>2 \alpha$, where $\theta_{0}$ is defined by equation (18). The transfer accelerates stabilization with certainty if $\left(\theta_{v}+1 / 2\right) \mu \geq 2 \alpha$, where $\theta$, is defined by equation (19).

Proposition A states that equation (21) is a necessary condition, and equation (20) a sufficient condition, for hastening stabilization.

At this level of detail, it is difficult to make reasonable empirical guesses on the support of the parameter $\theta$ and evaluate the likelihood that $(20)$ and (21) will be satisfied. However, while the positive implications of the model remain ambiguous, the normative implications are simple and clear. Since both $T(\theta)$ and $T(\theta)$ are monotonic in $\theta$. Proposition $A$ can be rephrased as tollows:

Proposition A: If there is a delay between the time foreign aid is announced and the time it is disbursed. then there exist two dates $s^{\circ}$ and $v^{*}\left(s^{\circ}<v\right)$ such that foreign aid announced after $s^{\circ}$ will delay stabilization, while aid disbursed before $v^{*}$ will hasten it. $s^{*}$ is the solution to: $T(\theta)=$ $s^{*}$, and $v^{\circ}$ to: $T(\theta)=v^{\circ}$, where $\left(\theta^{\circ}+1 / 2\right) \mu=2 \alpha$.

Proposition $\mathrm{A}^{\prime}$ states that foreign aid can accelerate stabilization but that proper timing is essential: aid announced or delivered too late is counterproductive.

The result is particularly simple because $s^{\circ}$ does not depend on the size of the transfer. Whatever its amount, the announcement that aid is coming must be made before a critical date that depends on the structure of the economy, as captured by the parameters $r, \mu, \alpha$ and the support of $\theta$.

Proper timing is essential not only in announcing ajd but also in delivering it. A full characterization of the critical delivery date $v^{*}$ is complex since, unlike $s^{*}, v^{*}$ depends on the size of the transfer. "' Regardiess of the size of the transfer, however, the longer is the interval between announcement and disbursal, the higher is the probability that aid will delay stabilization. But shorter intervals accelerate stabilization only up to a point; as the interval 
grows short, the length of time during which the effects of the expected transfer are felt is also reduced, and the impact on the timing of stabilization tends to disappear.

Athough the size of the transfer is of secondary importance, it is not irrelevant. A larger transfer (a smaller $B$ ) causes a decline in $\sigma(t)$. As shown by equation (15), this accentuates the difference in the slope of the original path $T(\theta)$ and the new path $T(\theta)$ that is followed between $s$ and $v$. Two implications follow. First, the larger the transfer the higher the retum from getting the timing right. If the announcement of aid comes too late and condition (21) is violated, the expected date of stabilization is delayed longer the larger is the size of the transfer. Conversely, if the timing of both announcement and disbursal is chosen correctly, the date of stabilization is hastened more the larger is the transfer. Second, the larger the transfer, the shorter must be the interval between announcement and disbursal for stabilization to be hastened. Suppose the transfer has been announced early enough, so that $T(\theta)$ is flatter than the original path at $\theta$. Then the critical moment when the marginal player is of type $\theta^{\circ}$ is reached earlier, and from that moment onward $T(\theta)$ is steeper than the original function. The larger the transter, the larger the difference in slopes at time $\mathrm{S}$, and the earlier the moment when $T(\theta)$ becomes steeper than $T(\theta)$. Therefore, the larger is the transfer, the shorter must be the interval between announcement and disbursal for condition $(20)$ to be satisfied.

Why is timing so important? As mentioned above, a transfer has two effects: it lowers the lifetime cost of conceding by reducing the fiscal burden on the loser; at the same time it increases the marginal benefit of postponing concession until the transfer has arrived, since this means avoiding a number of periods when still-high fiscal deficits must be financed by the loser. The relative importance of the two effects depends on the welfare costs of distortionary taxation. If these costs are high, the first effect dominates: even taking Into account the temptation to wait until the transfer arives, the reduction in the cost of losing is sufficient to accelerate concession. If, on the other hand, the costs of distortionary taxation are low, it 
makes sense to hold out longer in order to approach the time when the cost of losing is reduced by the artival of aid. When the transfer is announced and disbursed early, high cost players are still in the game. For them the first effect dominates: earlier concession is now optima, and if no concession is observed each player has additional information with which to update his estimate of his opponent's cost. When high $\theta$ s are still in the game, the announcement of a transfer hastens the rate at which information about types is conveyed. But if the announcement is late, players already know that both have relatively low costs. Such players will want to wait for the transfer to arrive and the fact that no concession takes place conveys little new information about the opponent's type. Stabilization is delayed because the acquisition of information is slowed down. To summarize, timing matters because an expected transfer creates different incentives for high and low cost players. As a result, the transfer affects the rate at which information is revealed, accelerating stabilization if the timing is correct but delaying it otherwise.

We conclude our discussion with a few remarks on the role of the parameters $\alpha$ and $\mu$. While equations (20) and (21) make clear that the values of $\alpha$ and $\mu$ influence the results, in general their impact is ambiguous. Consider first $\alpha$, which we interpret as a measure of the polarization of society, following Alesina and Orazen. The higher is $\alpha$ - the more costly it is to concede - the higher $\theta$, and $\theta_{v}$ must be to satisty (20) and (21). At the same time, the higher is $a$ the slower is the rate of concession in the original game, and therefore the higher is the $\theta$ characterizing players still in the game at any point in time. Slnce these two effects work in opposite directions, the length of time after which foreign aid becomes counterproductive may become longer or shorter as the distributional fight becomes more polarized. The same reasoning applies to $\mu$. The larger $\mu$ - the greater the recourse to distortionary taxation - the lower $\theta$, and $\theta$. must be to satisty (20) and (21). But the larger $\mu$ the higher the original rate of concession, and the lower the idiosyncratic costs bome by players still in the game at any 
given time. Again, it is not clear whether greater recourse to distortionary taxation advances or delays the date after which aid is counterproductive."

\section{DISCUSSION}

Alesina and Drazen built their model with the goal of analyzing a rational delay in stabilization as the outcome of a distributional war of attrition. Other models could produce similar results. Bargaining models are a natural alternative, where delay could result from incomplete information (as in, for example. Admati and Perry, 1987) or from the richness of the players' strategies even when intormation is complete (as in Femandez and Glazer, 1991). In our opinion, however, the representation of the problem as a war of attrition is sutficientiy taithtul to historical experience to be the appropriate starting point.

How sensitive are our results to the particular simplifying assumptions adopted by Alesina and Drazen? As they note, the main weakness of their model is the absence of money: while it is natural to interpret the distortionary taxes financing the deficit before stabilization in terms of inflation, no explicit monetary mechanism is present. For our purposes, this has two implications. First, the specification of the welfare costs of inflation is arbitrary. The model provides little intuition about the right way to link those costs to the size of the deficit. Second, and more troubling, the model excludes the role of expectations: a reduction in public deficit causes a commensurate reduction in distortionary taxation at exactly the moment it occurs and has no effect before that time, even it it is anticipated.

The full specification of a monetary economy is beyond the purposes of this note. Here we limit ourselves to a few observations.

With respect to the first point, the proportional link between distortionary taxation and welfare costs is responsible for the conclusion that unexpected transfers have no impact on the 
date of stabilization. However, we can easily think of other specifications under which this result would be modified. Suppose for example that we wanted to capture the intuitive scenario where welfare costs rise less than proportionally with inflation for low inflation rates, and more than proportionally with high inflation rates: welfare costs are initially concave and then convex in distortionary taxation. Since different agents have different abilities to protect themselves from the distortion, both the level of the costs and the threshold of inflation corresponding to the inflexion point of the costs function depend on the agents' type. In a simple linear approximation, the specification of flow utility before stabilization becomes:

$$
u_{1}=-\max \left(0, \tau_{1}+\theta_{1}-c\right)-1 / 2 \tau_{1} \quad \forall \tau_{1}>0
$$

where $c$ is a constant. The costs of distortionary taxation are positive only when it rises beyond a certain threshold that depends on $\theta_{1}$. A necessary condition for an unexpected transter to be stabilizing is that its impact on the deficit is larger than its impact on welfare costs for the marginal player willing to concede at the time the transfer takes place. With specification ( $\left.3^{\prime \prime}\right)$. this condition amounts to requining $\theta_{v}>c_{1}$ where $\theta_{v}$ characterizes the marginal player at the time the transfer is effected: players with sufficiently high welfare costs must still be in the game when the transfer occurs. Once again, this is equivalent to a restriction on timing: for aid to be stabilizing it must be disbursed sufficiently early. ${ }^{\text {s }}$

More generally, a transfer will accelerate stabilization if its effect on future deficits is larger than its immediate effect on inflation. Thus it is more likely to hasten stabilization in an economy where inflation has an inertial component (due for example to the existence of long term nominal contracts). Since inertia tends to disappear as the economy approaches hyperinflation, we expect aid to be more effective in addressing distributional conflicts when inflation is not yet out of control. Despite their impressionistic nature, these considerations support our conclusion on the importance of timing. 
We have derived rigorously such conclusion in the analysis of an expected transfer, and it is in this context that Ignoring expectations can be particularly misleading. It is important to show that the result is not modified when we allow the public discussion of a future transfer to affect immediately expectations of future monetization.

Suppose that each player's welfare costs depend not only on the current level of distortionary taxation but also on his expectations of future distortionary taxes. Consider player

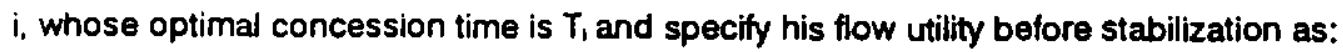

$$
\begin{aligned}
& u_{1}=-\left(\theta_{1}+1 / 2\right) \tau_{1}-\theta_{i}\left[\left(\operatorname{Prob} T\left(\theta_{i}\right) \geq T_{i}\right) \int_{1}^{T} \tau_{2} e^{+100} d s+\right. \\
& \left.+\int_{(\theta) r(\omega)<\pi)} \int_{1}^{\pi(n)} \tau_{0} e^{-(\infty) 1)} d s f(\theta) d \theta\right]
\end{aligned}
$$

where the probability that the opponent is more patient (Prob $T\left(\theta_{1}\right) \geq T_{1}$ ) is conditional on him not having conceded as of time $t$, and where the discount rate $r$ is large enough to guarantee that $u$, is falling in $\theta_{i}$ for all $t$ - a condition now not automatically satisfied. The terms in square brackets in equation ( $\left.3^{\prime \prime}\right)$ sum to the discounted stream of expected future distortionary taxes, which depends on the expected date of stabilization, itself a function of the probability that the opponent is more patient (the first term in the brackets) or less patient (the second term) than player $i$. This specification leads to results that are in fact identical to those of the previous section. The intuition is simple: at the margin each player considers the cost of postponing his concession by evaluating the welfare cost of staying in the game for another instant at time $T$. But at time $T$ his expectation of future distortions is necessarily zero since the game is ending: only the present distortion matters. The marginal condition must be identical to the one derived above. As long as the problem is well-behaved and the boundary condition unchanged, we are back to the set-up studied in the earlier section of the paper. An 
announced future transfer affects flow utilities before stabilization but still leads to the same marginal condition. Allowing for forward-tooking expectations does not affect our conclusions."

\section{CONCLUSIONS}

This paper has analyzed the conditions under which foreing ajd can help to accelerate stabilization. We have modeled the persistence of inflation as the byproduct of a distributional war of attrition. In this model, the policies of adjustment needed to halt the inflation are delayed not because their need is unappreciated but because each distributional faction seeks to shift the cost of implementation onto its rivals. We show that the timing of foreign assistance is critical in conditioning its effects. Ald announced and disbursed relatively early in the inflation process can accelerate stabilization. while ajd announced or delivered after a considerable delay will have exactly the opposite effect. 
Figure 1

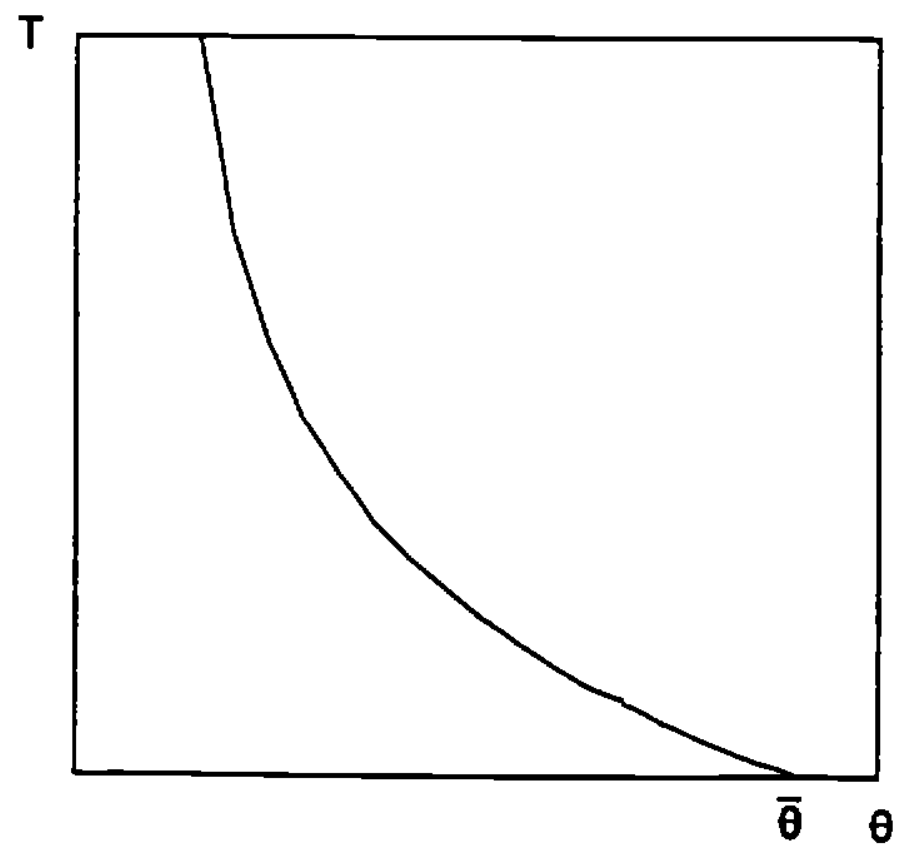


Figure 2a

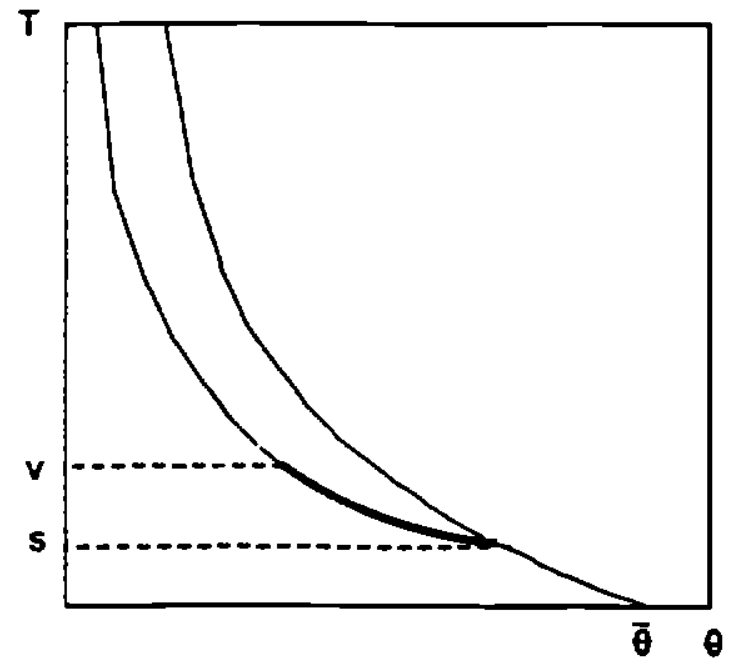

Figure $2 c$

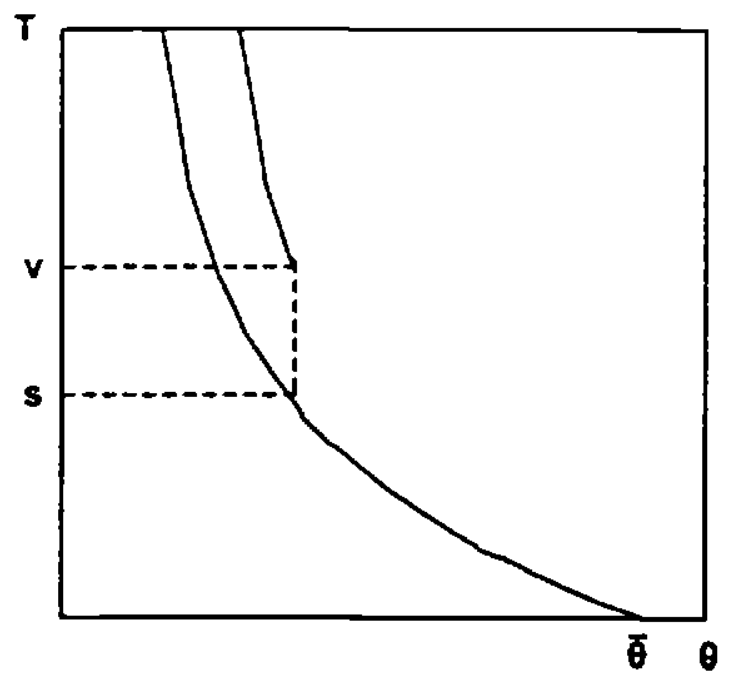

Figure 2b

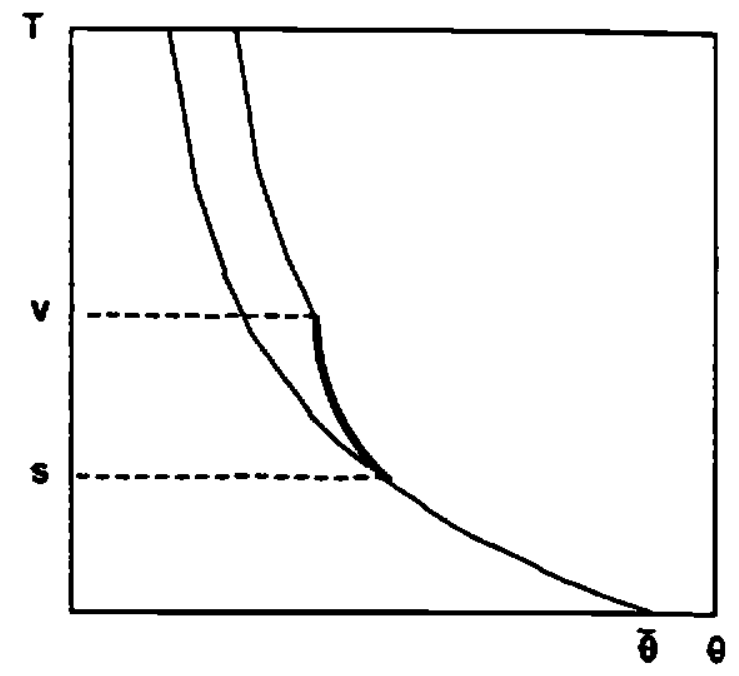

Figure $2 d$

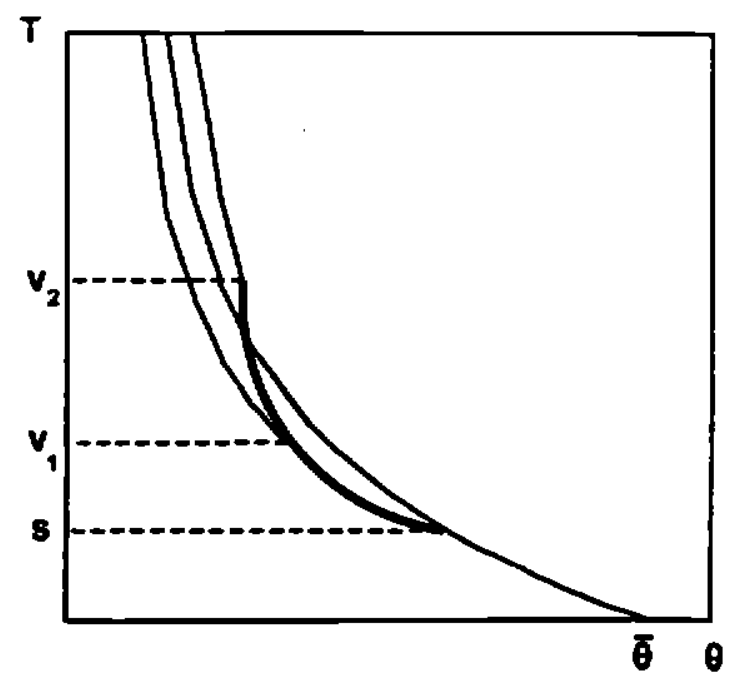




\section{FOOTNOTES}

- We thank Aberto Alesina, Mike Crosswell, Alan Drazen, Sebastian Edwards, Raquel Femandez, Bob Powell and especially Eddie Dekel-Tabak, Richard Gilbert, Matthew Rabin and Paul Romer for discussions and advice. Alessandra Casella thanks the Institute for Policy Reform (IPA) and the Agency for International Development (AID) for financial support This paper was prepared under a cooperative agreement between IPR and AD, Cooperative Agreement No. PDC-0095-A-00-1126-00. Views expressed in this paper are those of the authors and not necessarily those of IPR or AD. Barry Eichengreen thanks the National Science Foundation for research support.

1. See for example Alison and Yavlinski (1991) and Sachs (1994).

2. A representative statement of this view is Eberstadt (1992).

3. For details, see Maier (1975), Echengreen (1992) and Feldman (1993).

4. See Sargent (1986) and Santaella (1993).

5. See for example Rothschild (1992), pp. 53-54.

6. Casella and Echengreen (1993). The view that distributional struggles were responsible for delayed and contradictory policy measures is shared by other authors. See for example De Cecco (1968) and De Cecco and Giavazzi (1993).

7. See for example the contributions to Williamson (1983).

8. If ajd is used only to withdraw public debt, or only to finance direct govemment expenditure, the mathematical expressions are less simple but the substance of the analysis is unchanged.

9. Throughout the paper, we assume that the disbursement of the transfer takes place at a given date with certainty. Uncertainty may be added to the analysis, but the more interesting its source the more complex the extension. If there is uncertainty about whether or not the transfer will take place, but it is known that if the transfer takes place at all it must take place at $v$, then the problem is identical to the discussion in the text, with a minor reinterpretation. However if the date of the trasfer is uncertain, then the analysis changes non trivialy because estimates are updated with the passage of time. Note also that although the transfer is certain to occur at date $v$, the receiving country is not allowed to borrow immediately against it. The constraint seems realistic.

10. In symbols, and referring to equation (6), the first effect causes a decline in the term $\mathrm{N}^{\mathrm{m}}$. $V y$, the second an increase in $\mathrm{dV} / \mathrm{dT}$. 11. Given the time of the announcement $s$, the impact is largest if $v$ is chosen so that (20)
holds with equality.

12. A simple example makes the point immediately. Suppose the distribution of $\theta$ is uniform over the interval $[1,10], r=10$ percent, $\mu=1$ (alf fiscal expenditure before stabilization is 
financed with distortionaty taxes) and $\alpha=1$ (the loser shoulders the entire fiscal deficit). Then equations (10) and (21) imply that any foreign aid, of whatever size, must be announced before 12.8 periods have elapsed. The interest rate is the anchor implicitly defining the length of the period. It enters the expression in a simple multiplicative fashion: for example, if all other parameters are as in the text but the interest rate is halved to 5 percent, the maximum number of periods is doubled to 25.6. If we ignore compounding, the presence of the interest rate insures that the arbitrary choice of the length of the period does not affect the result.

\section{Notice that $T(\theta)$ depends on $B$.}

14. A little more can be said if we assume a specific distribution for $\theta$. For example, if the distribution is uniform, equations (10) and (21) Imply that $s^{\prime}$ increases with $\alpha$ if $\mu$ is low, but falls as $\alpha$ rises if $\mu$ is high. On the other hand, $s$ falls monotonically with $\mu$. The lack of a closed form solution for $T(\theta)$ prevents us from adding anything on the link between $a, \mu$ and $v$.

15. Notice that $\theta_{0}>c$ implies a negative threshold for distortions: i.e. distortionary taxation is costly for type $\theta$, even if it is very small, as long as it is positive. For all $\theta \geq \theta$. welfare costs have a discontinuity at $\tau=0$. The restriction $\underline{\theta}>c-\tau_{0}(3 / 2-\alpha)$, implying that welfare costs are positive for all players already at time 0 , is sutficient to guarantee that the the game is wellbehaved.

16. The counterintuitive conclusion that expectations do not matter depends on the assumption that welfare costs are a function of individual expectations of future distortions which can then be manipulated by individual action (concession). Notice that these expectations, although rational, differ between the two players since each one knows his own idiosyncratic cost $\theta$. An alternative specification would have the expectation of future distortions, which is the proxy for inflation, be formed by an outside observer. Each player would take this expectation as given and could not affect it be conceding, and expected future events would appear in the marginal condition. However, if an equilibrium strategy exists, we believe that the substance of our conclusion would not be modified. Suppose that the timing of the transfer were such as to induce earlier stabilization, ignoring expectations. The shorter horizon reduces future expected distortionary taxes and therefore current welfare costs and the incentive to stabilize. But in equilibrium the effect of expectations cannot be strong enough to delay the expected date of stabilization: otherwise the horizon would be longer and the incentive to stabilize even stronger than without expectations. In other words, the change in the slope of the $T(\theta)$ function in response to news of a future transter may be reduced but cannot switch sign. We find the assumption of an extemal observer forming expectations that directly affect individual utility very artificial and do not pursue it further. 


\section{REFERENCES}

Admati, Anat and Motty Perry, 1987, "Strategic Delay in Bargaining", Review of Economic Studies LIV, pp.345-364.

Alesina, Alberto and Alan Drazen, 1991, "Why Are Stabilizations Delayed?". American Economic Review, December, pp.1170-1188.

Alison, Graham and Grigory Yavtinski, 1991, Window of Opportunity, New York: Pantheon.

Casella. Alessandra and Barty Echengreen, 1993, "Halting Inflation in Italy and France After World War $11^{\circ}$, in Michael Bordo and Forrest Capie (eds.), Monetary Reqimes in Transition, Cambridge: Cambridge University Press.

De Cecco, Marcello, 1968. "Sulla politica di stabilizzazione del 1947" in Sagqi di politica monetaria Milano: Giuffre'.

De Cecco, Marcello and Francesco Giavazzi, 1993, "Inflation and Stabilization in Italy: 1946$1951^{\circ}$, in Rudiger Dombusch. Wilhelm Nolling and Richard Layard (eds.). Post-War Economic Reconstruction and Lessons for the East Today Cambridge, MA: MIT Press, pp.57-82.

Eberstadt. Nicholas, 1992, "Wrongheaded Aid to Russia", Wall Street Journal, (1 September). p.A14.

Elchengreen, Barty, 1990, "The Capital Levy in Theory and Practice", in Mario Draghi and Rudiger Dombusch (eds.). Public Debt Management: Theory and History Cambridge: Cambridge University Press.

Eichengreen, Barry, 1992, Golden Fetters: The Gold Standard and the Great Depression, 19191959, Oxford: Oxford University Press.

Ejchengreen, Barry and Marc Uzan, 1992, "The Marshall Plan: Economic Ettects and Implications for Eastem Europe and the Former USSR", Economic Policy 14.

Feldman, Gerald, 1993. The Great Disorder, New York: Oxford University Press.

Fernandez, Raquel and Jacob Glazer, 1991. "Striking for a Bargain Between Two Completely Informed Agents", American Economic Review March, pp.240-252.

Maier, Charles, 1975, Recasting Bourgeoise Europe, Princeton: Princeton University Press.

Rothschild, Joseph, 1992, East Central Europe Between the Two World Wars, Seatte:

University of Washington Press.

Sachs, Jeffrey, 1994, "Betrayal', New Republic, 31 January, pp.14-18.

Santaella, Julio, 1993, 'Stabilization Programs and External Enforcement', IMF Staff Papers, 40, September, pp.584-62t. 
Sargent, Thomas, 1986, Rational Expectations and Inflation, New York: Harper and Row. Williamson, John, 1983, IMF Conditionality, Washington, D.C.: Institute for International Economics. 